\title{
Collecting and Collectors
}

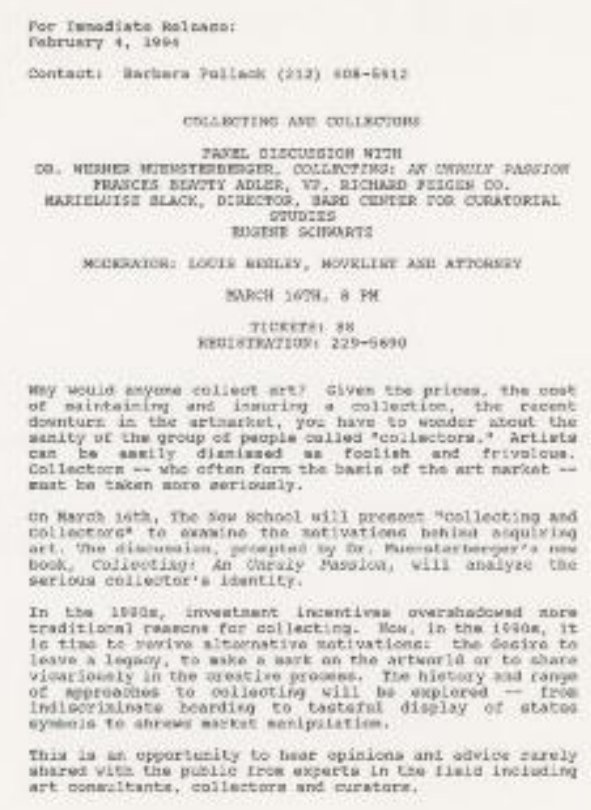

\section{Related Collection}

New School Office of Communications, George Calderaro records $\rightarrow$ Binders (NS030103.01)

\section{Description}

This item constitutes part of Public Relations Books 1-3. While the majority of records compiled into the books are press releases, other formats may be present.

\section{Date}

1994

\section{Related person}

(author)

New School for Social Research (New York, N.Y. : 1919-1997)(author)

\section{Work Type}

press releases

Page 1 of 2 


\section{Use Restrictions}

http://rightsstatements.org/vocab/lnC/1.0/

\section{Location}

box 1 , folder 18

Identifier

NS030103_000011

Page 2 of 2 